\title{
EFICIÊNCIA AGRONÔMICA DE RIZÓBIOS EM FEIJÃO DE PORCO PARA FINS
} DE ADUBAÇÃO VERDE

Felipe Menine ${ }^{1}$, Diego Mathias Natal da Silva ${ }^{2}$, Thiago Pacheco Mendes ${ }^{3}$, Ralph Bonandi Barreiros ${ }^{4}$, Fábio Luiz de Oliveira ${ }^{5}$

1. Graduando em Agronomia pelo Centro de Ciências Agrárias da Universidade Federal do Espírito Santo (CCA /UFES), (felipemarcatemenine@gmail.com) Alegre- ES, Brasil

2. Pós- Doutorando em Produção Vegetal pelo Centro de Ciências Agrárias da Universidade Federal do Espírito Santo (CCA-UFES), Alegre- ES, Brasil

3. Graduando em Agronomia pelo Centro de Ciências Agrárias da Universidade Federal do Espírito Santo (CCA /UFES), Alegre- ES, Brasil

4. Graduando em Agronomia pelo Centro de Ciências Agrárias da Universidade Federal do Espírito Santo (CCA /UFES), Alegre- ES, Brasil

5. Professor Doutor do Departamento de Produção Vegetal da Universidade Federal do Espírito Santo, Alegre- ES, Brasil

Recebido em: 08/04/2016 - Aprovado em: 30/05/2016 - Publicado em: 20/06/2016 DOI: 10.18677/Enciclopedia_Biosfera_2016_048

\section{RESUMO}

A adubação verde ajuda reduzir os impactos causados pelos sistemas de produção intensivos, contribuindo para a preservação do solo. Objetivou-se com esse trabalho a validação da eficiência agronômica de diferentes estirpes de rizóbios para fins de recomendação para inoculação em feijão de porco (Canavalia ensiformis) utilizado na adubação verde. Para obtenção dos resultados avaliou-se após 30 dias do plantio, o número e massa seca de nódulos formados nas raízes e massa seca da parte aérea. Posteriormente com o desenvolver do ciclo da cultura mediu-se o teor de clorofila nas folhas, massa seca do caule, folha e massa seca total, teor e acúmulo total de nitrogênio na parte aérea. O experimento foi conduzido entre os meses de novembro (2014) a abril (2015), em delineamento de blocos casualizados com quatro repetições, com parcelas de $24 \mathrm{~m}^{2}$. Sendo os tratamentos: 1) ausência de inoculação; 2) inoculação com a estirpe SEMIA 6156; 3) inoculação com a estirpe CPAO 76.2; 4) inoculação com a estirpe F2 (1); 5) inoculação com a estirpe F2- (2B) e 6) inoculação com a estirpe CPAC-B10. De acordo com os resultados obtidos na primeira avaliação as estirpes F2 (1) e F2 (2B) proporcionaram uma maior nodulação das plantas inoculadas. Devido às condições desfavoráveis do clima durante os meses de cultivo, não foi possível afirmar quais estirpes alcançariam melhores produções, entretanto, preliminarmente as estirpes F2 (1) e F2 (2B) apresentaram potencial de inoculação com o feijão de porco.

PALAVRAS-CHAVE: Canavalia ensiformis, Leguminosas, Rhizobium.

\section{AGRONOMIC EFFICIENCY OF RHIZOBIA IN JACK BEAN FOR PURPOSES OF GREEN MANURE}

\section{ABSTRACT}

Green manuring help reduce the negative impacts of intensive production systems, contributing to soil preservation. The objective of this work was the validation of the agronomic efficiency of different strains for recommendation purposes for inoculation 
in Jack bean (Canavalia ensiformis) used in green manure. To obtain the results were evaluated 30 days after planting, the number and dry weight of nodules formed on the roots and dry mass of shoots. Later with the development of the crop cycle was measured chlorophyll content in the leaves, dry mass of the stem, leaf and total dry matter, and total accumulation of nitrogen in the shoot. The experiment was conducted during the months of November (2014) to April (2015), in a randomized block design with four replications, with $24 \mathrm{~m}^{2}$ plots. The treatments: 1) no inoculation; 2) inoculation with the strain SEMIA 6156; 3) Inoculation with strain 76.2 CPAO; 4) Inoculation with strain F2 (1); 5) inoculation with the strain F2 (2B) and 6) CPAC-inoculation with the B10 strain. According to the results of the first assessment F2 strains (1) and F2 (2B) were provided greater nodulation of inoculated plants. Due to unfavorable weather conditions during the months of cultivation, it was not possible to say which strains would reach best productions, however, it is permissible to select strains of rhizobia to establish an effective symbiosis with the canavalia.

KEYWORDS: Canavalia ensiformis,, Legumes, Rhizobium.

\section{INTRODUÇÃO}

A utilização da adubação verde viabiliza a manutenção dos solos agrícolas, principalmente pela reciclagem de nutrientes e aporte de $\mathrm{N}$, melhorando a fertilidade das áreas cultivadas (FERREIRA et al., 2016), influenciando diretamente na redução dos custos com fertilizantes.

Diversas espécies apresentam potencial que permitem ser empregadas como plantas de adubação verde, entretanto, as leguminosas são as mais utilizadas. Além de produzirem grande quantidade de fitomassa promovendo a cobertura do solo, também realizam a fixação biológica do nitrogênio (FBN) atmosférico em simbiose com bactérias do gênero Rhizobium. Com isso, destaca-se a utilização do Feijão de porco (Canavalia ensiformis) pela facilidade de associação, após a inoculação das sementes com bactérias fixadoras de nitrogênio (BRASIL, 2010; PROGRAMA ABC, 2010), conjunto ao elevado potencial de adição de matéria seca para cobertura do solo (TEODORO et al., 2011).

Segundo BROCKWELL et al., (1995), a eficácia da simbiose de cada estirpe varia de acordo com a planta hospedeira. Considerando que a maior produção de inoculantes no país está voltada para a redução de gastos com fertilizantes nitrogenados na cultura da soja (HUNGRIA et al., 2005; HUNGRIA et al., 2007), destaca-se a importância de novos estudos para a otimização do processo de FBN que, por conseguinte, atribui benefícios para a sociedade (MENNA et al., 2011).

O presente trabalho tem por objetivo a avaliação da eficiência agronômica de estirpes de bactérias fixadoras de nitrogênio no feijão de porco para fins de produção de inoculantes comerciais.

\section{MATERIAL E MÉTODOS}

O trabalho foi conduzido entre os meses de novembro de 2014 a abril de 2015 na Área Experimental do Centro de Ciências Agrárias da Universidade Federal do Espírito Santo (CCA-UFES), localizada no município de Alegre, ES, tendo como coordenadas geográficas do local $20^{\circ} 46$ '2, $8^{\prime \prime}$ de latitude Sul e $41^{\circ} 27^{\prime} 39,2^{\prime}$ de longitude Oeste e altitude de $120 \mathrm{~m}$.

O experimento foi instalado obedecendo ao delineamento em blocos casualizados com quatro repetições. Os tratamentos foram constituídos pela inoculação de diferentes estirpes de bactérias fixadoras de nitrogênio do gênero 
Rhizobium em sementes de feijão de porco: 1) ausência de inoculação; 2) inoculação com a estirpe SEMIA 6156; 3) inoculação com a estirpe CPAO 76.2; 4) inoculação com a estirpe F2 (1); 5) inoculação com a estirpe F2 (2B); 6) inoculação com a estirpe CPAC-B10. Para a inoculação, as sementes foram umedecidas em solução de sacarose a $10 \%$ e misturadas com o inoculante à base de turfa, com a quantidade mínima de UFC (Unidades formadoras de colônias) da estirpe inoculante recomendada, levando-se em conta a quantidade de células por semente.

A unidade experimental foi constituída de doze linhas de semeadura de $4 \mathrm{~m}$, espaçadas de 0,5 m entre linhas e 0,1 m entre sementes, totalizando uma área de $24 \mathrm{~m}^{2}$, no entanto, as duas linhas de cada extremidade, assim como as cinco plantas da extremidade de cada linha não foram utilizadas na avaliação.

O solo foi preparado por meio de aração a $30 \mathrm{~cm}$ seguida de gradagem e foi classificado como Latossolo Vermelho-Amarelo, cuja amostra foi submetida ao Laboratório de Solos do Centro de Ciências Agrárias da Universidade Federal do Espírito Santo para análises química e física, que apresentaram as seguintes características na camada de 0 a $20 \mathrm{~cm}$ : pH 6,37 em água; $36,99 \mathrm{mg} \mathrm{dm}^{-3}$ de $\mathrm{P}$ Mehlich $;$; $57,00 \mathrm{mg} \mathrm{dm}^{-3}$ de K; $1,50 \mathrm{cmol}_{\mathrm{c}} \mathrm{dm}^{-3}$ de $\mathrm{Ca} ; 0,71 \mathrm{cmol}_{\mathrm{c}} \mathrm{dm}^{-3}$ de $\mathrm{Mg} ; 0,0$ $\mathrm{cmol}_{\mathrm{c}} \mathrm{dm}^{-3}$ de Al; $1,32 \mathrm{cmol}_{\mathrm{c}} \mathrm{dm}^{-3}$ de H $+\mathrm{Al} ; 2,36 \mathrm{cmol}_{\mathrm{c}} \mathrm{dm}^{-3}$ de SB; $2,36 \mathrm{cmol}_{\mathrm{c}} \mathrm{dm}^{-3}$ de t; $3,68 \mathrm{cmol}_{\mathrm{c}} \mathrm{dm}^{-3}$ de T; $64,09 \%$ de V; e $0,0 \%$ de m; areia $60 \%$, silte $5 \%$ e $35 \%$ de argila.

O clima da região Sul do Espírito Santo é do tipo "AW", com duas estações bem definidas durante o ano, sendo uma quente e chuvosa entre os meses de outubro a março e outra fria e seca nos meses de abril a setembro, temperatura anual média de $23^{\circ} \mathrm{C}$, precipitação anual em torno de $1.200 \mathrm{~mm}$. As médias mensais de temperatura média e precipitação esperada e ocorrida estão representadas na Figura 1 e foram obtidas através da estação meteorológica do INMET no município de Alegre $\left(20,751^{\circ}\right.$ de latitude Sul, $41,489^{\circ}$ de long itude Oeste e $138 \mathrm{~m}$ de altitude).

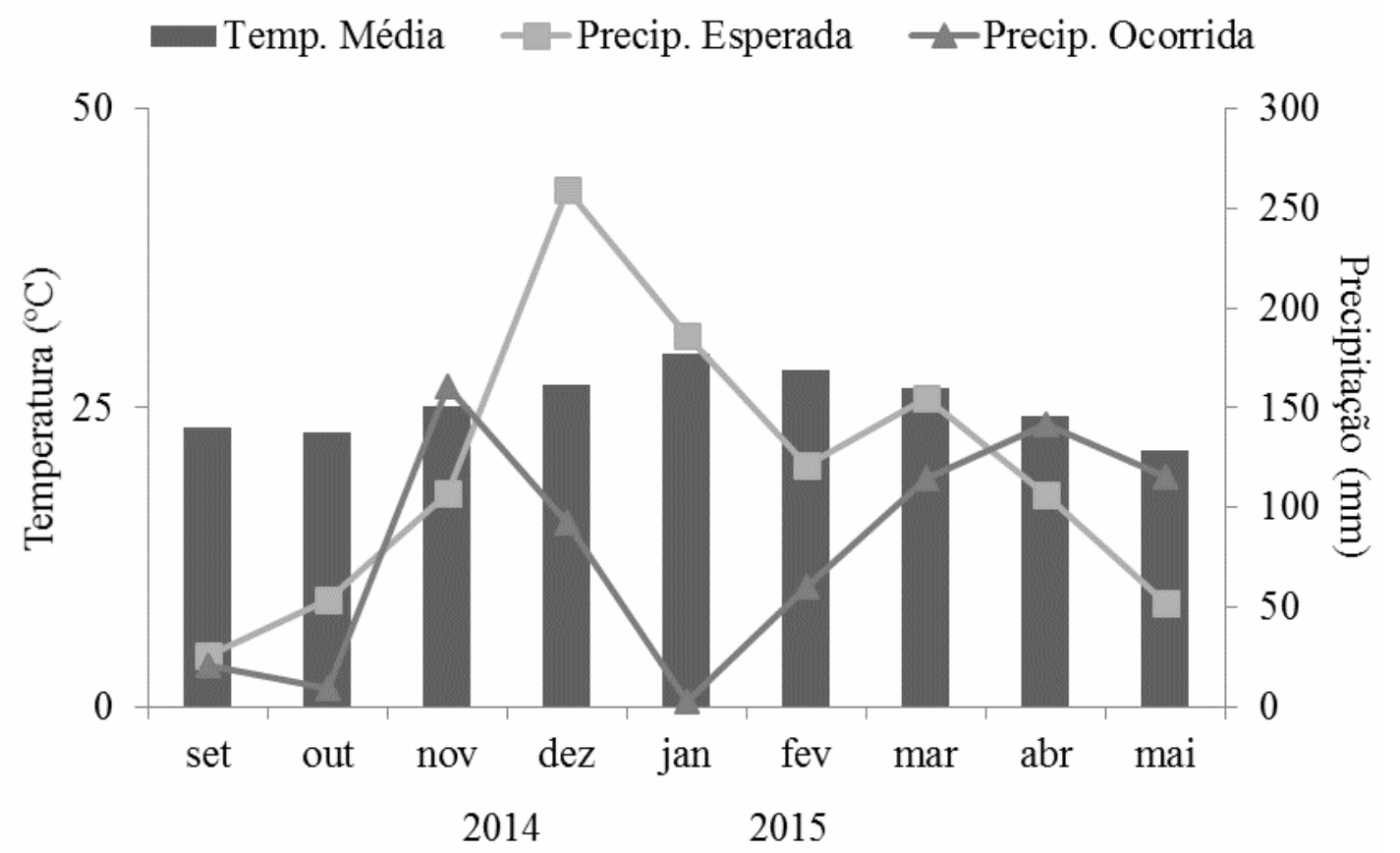

FIGURA 1. Médias mensais de temperatura média e precipitação esperada e ocorrida observadas no período de setembro de 2014 a maio de 2015 no município de Alegre, ES. Fonte: INCAPER (2015).

Aos 30 dias após a semeadura (DAS) foram avaliados o número e a massa ENCICLOPÉDIA BIOSFERA, Centro Científico Conhecer - Goiânia, v.13 n.23; p. 542 
seca de nódulos e a massa seca da parte aérea. $O$ teor de clorofila (medido no ClorofiLOG® modelo CFL 1030 - Falker) foi avaliado aos 30, 60 e 90 DAS. Aos 180 DAS foram avaliados a massa seca do caule e da folha e a massa seca total, assim como o teor e o acúmulo de nitrogênio da massa seca total. Para obtenção da massa seca os órgãos da planta foram secos em estufa com circulação forçada de ar a $70 \pm 5^{\circ} \mathrm{C}$ até massa constante e o teor de $\mathrm{N}$ foi determinado após digestão sulfúrica e destilação em Kjeldahl (BREMNER \& MULVANEY, 1982).

As análises estatísticas foram realizadas com auxílio do programa estatístico SISVAR (FERREIRA, 2008). Os dados obtidos foram submetidos à análise de variância e as médias, quando significativas, comparadas pelo teste de Tukey, a 5\% de probabilidade.

\section{RESULTADOS E DISCUSSÃO}

Conforme apresentado na Figura 1, durante o ciclo de cultivo do feijão de porco a planta ficou exposta ao estresse hídrico e elevadas temperaturas, fato que prejudicou a sua produção de biomassa, mesmo sendo uma planta resistente a variações climáticas (CALEGARI et al., 1993; CARVALHO et al., 1999) e de crescimento inicial rápido, interferindo diretamente nos resultados esperados.

Aos 30 dias após a semeadura (DAS), as plantas inoculadas com as estirpes F2 (1) e F2 (2B) apresentaram um maior número de nódulos e destacaram-se das demais que não diferiram entre si, confirmando os resultados encontrados por SILVA et al., (2007), porém, os nódulos cujas plantas foram inoculadas com a estirpe F2 (1) tiveram maior valor numérico de massa seca, o que também foi concluído por FERNANDES et al., (2003), e foi o único tratamento que se diferenciou da estirpe CPAC B10 que obteve o menor valor de massa seca de nódulos. Quanto à massa seca da parte aérea os tratamentos não apresentaram diferenças entre si, o que pode ser justificado pelo crescimento inicial rápido e homogêneo das plantas (CARVALHO \& SODRÉ FILHO, 2000).

TABELA 1 - Número e massa seca de nódulos em raízes, e massa seca da parte aérea do feijão de porco inoculado com diferentes estirpes de Rhizobium, aos 30 dias após a semeadura. Alegre, UFES, 2014/15.

\begin{tabular}{lccc}
\hline Estirpes & $\begin{array}{c}\text { Número de } \\
\text { nódulos }\left(\mathrm{ha}^{-1}\right)\end{array}$ & $\begin{array}{c}\text { Massa seca de } \\
\text { nódulos }\left(\mathrm{Kg} \mathrm{ha}^{-1}\right)\end{array}$ & $\begin{array}{c}\text { Massa seca da parte } \\
\text { aérea }\left(\mathrm{t} \mathrm{ha}^{-1}\right)\end{array}$ \\
\hline${ }^{*}$ SI & $1030000 \mathrm{~b}$ & $36 \mathrm{ab}$ & $0,72 \mathrm{a}$ \\
SEMIA 6156 & $1390000 \mathrm{~b}$ & $40 \mathrm{ab}$ & $0,78 \mathrm{a}$ \\
CPAO 76.2 & $1400000 \mathrm{~b}$ & $38 \mathrm{ab}$ & $0,72 \mathrm{a}$ \\
F2 (1) & $3510000 \mathrm{a}$ & $51 \mathrm{a}$ & $0,72 \mathrm{a}$ \\
F2 (2B) & $3065000 \mathrm{a}$ & $42 \mathrm{ab}$ & $0,64 \mathrm{a}$ \\
CPAC B10 & $940000 \mathrm{~b}$ & $32 \mathrm{~b}$ & $0,78 \mathrm{a}$ \\
\hline CV (\%) & 25,23 & 14,75 & 9,79
\end{tabular}

Valores seguidos de letras iguais não diferem entre si pelo teste Tukey, $\mathrm{p}<0,05 ;{ }^{*} \mathrm{SI}$ - sem inoculante.

Em relação ao teor de clorofila das folhas, não houve diferenças entre os tratamentos, demonstrando que, nas condições ambientais estudadas, as plantas de feijão de porco inoculadas não aumentaram a produção de clorofila quando 
comparadas com as plantas não inoculadas (SI) (Tabela 2). Isso ocorreu possivelmente em função das condições ambientais (Figura 1), principalmente umidade, não favoráveis à planta e às estirpes de bactérias fixadoras de nitrogênio utilizadas, assim como à simbiose entre elas, e consequentemente, não alterando a nutrição em nitrogênio.

SORATTO et al., (2004) em um experimento avaliando o teor de clorofila e produtividade do feijoeiro em razão da adubação, constatou que incrementos na dose de $\mathrm{N}$ em cobertura provocaram aumento do teor de clorofila, isto por que esse elemento faz parte da molécula de clorofila (MALAVOLTA et al., 1997), contribuindo para predizer o nível nutricional de nitrogênio (N) em plantas (BOOIJ et al., 2000).

TABELA 2 - Teor de clorofila (\%) nas folhas do feijão de porco inoculado com diferentes estirpes de Rhizobium aos 30,60 e 90 dias após a semeadura. Alegre, UFES, 2014/15.

\begin{tabular}{lccc}
\hline Estirpes & 30 dias & 60 dias & 90 dias \\
\hline${ }^{*}$ SI & $43,83 \mathrm{a}$ & $43,54 \mathrm{a}$ & $42,32 \mathrm{a}$ \\
SEMIA 6156 & $43,83 \mathrm{a}$ & $48,63 \mathrm{a}$ & $47,58 \mathrm{a}$ \\
CPAO 76.2 & $43,71 \mathrm{a}$ & $43,57 \mathrm{a}$ & $47,18 \mathrm{a}$ \\
F2 (1) & $41,88 \mathrm{a}$ & $47,64 \mathrm{a}$ & $48,47 \mathrm{a}$ \\
F2 (2B) & $41,43 \mathrm{a}$ & $47,22 \mathrm{a}$ & $45,69 \mathrm{a}$ \\
CPAC B10 & $44,37 \mathrm{a}$ & $45,94 \mathrm{a}$ & $45,94 \mathrm{a}$ \\
\hline CV (\%) & 7,71 & 8,44 & 10,64 \\
\hline
\end{tabular}

Valores seguidos de letras iguais não diferem entre si pelo teste Tukey, $\mathrm{p}<0,05 ;{ }^{*} \mathrm{SI}$ sem inoculante.

Aos 180 DAS também não foram observadas diferenças na produção de biomassa de caule, folha e total entre os tratamentos, sendo verificada de forma geral uma baixa produção de biomassa total, em torno de $2,12 \mathrm{t} \mathrm{ha}^{-1}$ de massa seca (Tabela 3). As condições do clima durante o ciclo de cultivo foi o principal motivo para inviabilizar a produção de biomassa. Dentre os fatores que interferem na produção das leguminosas, a sazonalidade é um dos mais influentes. FARIA et al., (2004) observaram para o feijão de porco uma menor produção de massa seca (3,309 $\left.\mathrm{t} \mathrm{ha}^{-1}\right)$ na época mais quente; enquanto que, na época mais fria, há um aumento nesta produção $\left(6,84 \mathrm{t} \mathrm{ha}^{-1}\right)$. PADOVAN et al., (2011) verificou diferenças na produção máxima da massa seca do feijão de porco em ecorregiões distintas, sendo tais diferenças, provavelmente, decorrentes das condições climáticas e edáficas das localidades (AMADO et al., 2002).

Para essa mesma espécie cultivado em Cerrado, TEODORO et al. (2011) verificaram uma produção de $8,77 \mathrm{t} \mathrm{ha}^{-1}$ de massa seca. Através de resultados obtidos por FAVERO et al., (2000) que comprovam o potencial das leguminosas em produzir biomassa, pode-se justificar e associar a baixa produção do feijão de porco, ao período climático desfavorável que a cultura se desenvolveu, impossibilitando melhores resultados ao ser associado com estirpes que potencializam as produções.

TABELA 3- Massa seca do caule, folha e total, 180 dias após a semeadura do feijão 
de porco inoculado com diferentes estirpes de Rhizobium. Alegre, UFES, $2014 / 15$.

\begin{tabular}{lccc}
\hline Estirpes & $\begin{array}{c}\text { Massa seca } \\
\text { do caule (t/ha) }\end{array}$ & $\begin{array}{c}\text { Massa seca } \\
\text { das folhas (t/ha) }\end{array}$ & $\begin{array}{c}\text { Massa seca } \\
\text { total }(\mathrm{t} / \mathrm{ha})\end{array}$ \\
\hline${ }^{*}$ SI & $1,02 \mathrm{a}$ & $1,09 \mathrm{a}$ & $2,11 \mathrm{a}$ \\
SEMIA 6156 & $0,97 \mathrm{a}$ & $0,98 \mathrm{a}$ & $1,95 \mathrm{a}$ \\
CPAO 76.2 & $1,13 \mathrm{a}$ & $1,13 \mathrm{a}$ & $2,26 \mathrm{a}$ \\
F2 (1) & $1,10 \mathrm{a}$ & $1,25 \mathrm{a}$ & $2,35 \mathrm{a}$ \\
F2 (2B) & $1,05 \mathrm{a}$ & $1,10 \mathrm{a}$ & $2,15 \mathrm{a}$ \\
CPAC B10 & $0,88 \mathrm{a}$ & $1,01 \mathrm{a}$ & $1,89 \mathrm{a}$ \\
\hline CV (\%) & 16,75 & 17,84 & 14,88 \\
\hline
\end{tabular}

Valores seguidos de letras iguais não diferem entre si pelo teste Tukey, $\mathrm{p}<0,05$; ${ }^{*} \mathrm{SI}$ - sem inoculante.

Os resultados do teor e acúmulo total de nitrogênio na parte aérea aos 180 DAS estão apresentados na Tabela 4. Observou-se que os tratamentos não se diferiram, evidenciando que a utilização das estirpes Rhizobium não contribuiu para aumentos de $\mathrm{N}$ nas plantas, relacionando-se ao teor de clorofila (Tabela 2) que também não demonstrou diferenças, já que esse elemento faz parte da molécula de clorofila (MALAVOLTA et al., 1997).

CARVALHO et al., ( 2003) avaliando a aplicação de $\mathrm{N}$ no solo em cobertura, constatou que, a medida que se aumenta a dose de $\mathrm{N}$, ocorre um incremento do teor de $\mathrm{N}$ nas folhas. $\mathrm{O}$ baixo acúmulo de nitrogênio na parte aérea pode ser explicado pela baixa produção de biomassa das plantas, que possui uma relação direta.

TEODORO et al., (2011), estudando os aspectos agronômicos de leguminosas para adubação verde, observou que o feijão de porco apresenta grande acúmulo de $\mathrm{N}$ quando a produção de biomassa é alta, e que os valores encontrados pelo aporte de $\mathrm{N}$ via fixação biológica de nutrientes, incluindo outras espécies de leguminosas, representam uma quantidade suficiente para suprir as necessidades de $\mathrm{N}$ de uma gama de culturas.

TABELA 4- Teor e acúmulo total de nitrogênio na parte aérea, 180 dias após a semeadura do feijão de porco inoculado com diferentes estirpes de Rhizobium. Alegre, UFES, 2014/15.

\begin{tabular}{lcc}
\hline Estirpes & Nitrogênio & Nitrogênio Acumulado \\
\hline & $\%$ & $\mathrm{Kg} / \mathrm{ha}^{-1}$ \\
\hline${ }^{*}$ SI & $2,2 \mathrm{a}$ & $46,42 \mathrm{a}$ \\
SEMIA 6156 & $2,2 \mathrm{a}$ & $42,90 \mathrm{a}$ \\
CPAO 76.2 & $2,2 \mathrm{a}$ & $49,72 \mathrm{a}$ \\
F2 (1) & $2,1 \mathrm{a}$ & $49,35 \mathrm{a}$ \\
F2 (2B) & $2,1 \mathrm{a}$ & $45,15 \mathrm{a}$ \\
CPAC B10 & $2,3 \mathrm{a}$ & $43,47 \mathrm{a}$ \\
CV (\%) & 8,84 & 18,92 \\
\hline
\end{tabular}

Valores seguidos de letras iguais não diferem entre si pelo teste Tukey, $\mathrm{p}<0,05$; ${ }^{*} \mathrm{SI}$ - sem inoculante. Fatores climáticos interferiram negativamente para a obtenção de melhores 
resultados, impossibilitando afirmar quais estirpes alcançariam melhores produções, porém é possível selecionar estirpes de rizóbios para estabelecer uma simbiose efetiva com o feijão de porco. Dessa forma, novas pesquisas envolvendo essas estirpes e o feijão de porco, devem ser feitas em condições ambientais mais favoráveis.

\section{CONCLUSÃO}

Nesses resultados preliminares, as estirpes F2 (1) e F2 (2B) quando utilizadas contribuem para uma maior nodulação das plantas de feijão de porco.

\section{AGRADECIMENTOS}

A FAPES, pelo auxílio financeiro à pesquisa e pela bolsa Pesquisador Capixaba. À UFES pela bolsa PIBIC.

\section{REFERÊNCIAS}

AMADO, T. J. C.; MIELNICZUK. J.; AITA, C. Recomendações de adubação nitrogenada para o milho no RS e SC adaptada ao uso de culturas de cobertura do solo, sob sistema plantio direto. Revista Brasileira de Ciência do Solo, Viçosa, MG, v. 26, n. 1, p. 241-248, 2002.

BOOIJ, R.; VALENZUELA, J.L. e AGUILERA, C. Determination of crop nitrogen status using non-invasive methods. In: HAVERKORT, A.J.; MACKERRON, D.K.L. (Eds.). Management of nitrogen and water in potato production. The Netherlands, Wageningen Pers, p.72-82, 2000.

BRASIL. Presidência da República. Decreto nํ 7.390, de 9 de Dezembro de 2010. Regulamenta os arts. 6으 11 e 12 da Lei no 12.187, de 29 de dezembro de 2009, que institui a Política Nacional sobre Mudança do Clima - PNMC, e dá outras providências. Diário Oficial da União, Brasília, DF, Seção 1,10 Dez. 2010.

BREMNER, J. M.; MULVANEY, C. S. Nitrogen total, In:PAGE, A. L.; MILLER, R. A.; KEENEY, D. R. (Ed.). Methods of soil analysis. 2. ed. Madison: American Society of agronomy, (Agronomy, 9), p. 595-624, 1982.

BROCKWELL, J.; BOTTOMLEY, P. J.; THIES, J. E. Manipulation of rhizobia microflora for improving legume productivity and soil fertility: A critical assessment. Plant and Soil, 174: 143-180, 1995.

CALEGARI, A.; ALCANTRA, P.B.; MIYASAKA, S. \& AMADO, T.J.C. Características das principais espécies de adubos verdes. In: COSTA, M.B.B., coord. Adubação verde no Sul do Brasil. Rio de Janeiro, AS-PTA, p.206-319, 1993.

CALEGARI, A.; MONDARDO, A.; BULISANI, E. A.; COSTA, M. B. B.; MIYASAKA, S.; AMADO, T. J. Aspectos gerais da adubação verde. In: COSTA, M.B.B. (Coord.). Adubação verde no sul do Brasil. 2. ed. Rio de Janeiro: Assessoria de Serviços a Projetos em Agricultura Alternativa, p. 1-55, 1993.

CARVALHO, A. M.; BURLE, M.L.; PEREIRA, J. \& SILVA, M.A. Manejo de adubos verdes no Cerrado. Embrapa Cerrados, (Circular Técnica, 4), p. 28, 1999. 
CARVALHO, A. M. de SODRÉ FILHO, J. Uso de adubos verdes como cobertura de solo. Planaltina, DF: Embrapa Cerrados, p. 20, 2000.

CARVALHO, M. A. C.; FURLANI, E. J.; ARF,O.; SÁ M. E.; PAULINO H. B.; BUZETTI S. Doses e épocas de aplicação de nitrogênio e teores foliares deste nutriente e de clorofila em feijoeiro. Revista Brasileira de Ciências do Solo, 27:445-450, 2003.

ESPÍNDOLA, J. A. A.; GUERRA, J. G.; ALMEIDA, D. L. de. Adubação verde: estratégia para uma agricultura sustentável. Seropédica: Embrapa Agrobiologia, p. 20, 1997.

FARIA, C. M. B. Comportamento de leguminosas para adubação verde no Submédio São Francisco. Petrolina: Embrapa Semiárido. (Boletim de pesquisa e desenvolvimento, 63), p. 22, 2004.

FAVERO C.; JUCKSCH I.; COSTA L. M.; ALVARENGA R. CNEVES. J. C. L. Crescimento e acúmulo de nutrientes por plantas espontâneas e por leguminosas utilizadas para adubação verde. Revista Brasileira de Ciências do Solo, 24:171177, 2000.

FERREIRA, D. F. SISVAR: um programa para análises e ensino de estatística. Revista Symposium, v. 06, n. 02, p. 36-41, 2008.

FERREIRA, M. E.; ANDRAUS, P. M.; CARDOSO, A. A.; COSTA, S. F. L.; LÔBO, M. L.; LEANDRO, M. W. Recuperação de áreas degradadas, adubação verde e qualidade da água. Revista Monografias Ambientais - REMOA v. 15, n.1, p.228246, jan-abr. 2016.

FERNANDES, M. F.; FERNANDES, R. P M.; HUNGRIA, M. Seleção de rizóbios nativos para guandu, caupi e feijão-de-porco nos tabuleiros costeiros de Sergipe. Pesquisa agropecuária brasileira. Brasília, v. 38, n. 7, p. 835-842, jul. 2003.

HUNGRIA, M.; FRANCHINI, J. C.; CAMPO, R. J.; GRAHAM, P. H. The importance of nitrogen fixation to soybean cropping in South America. In: WERNER, D. \& NEWTON, W., ed. Nitrogen fixation in agriculture, forestry, ecology, and the environment. Dordrecht, Springer, p. 25-42, 2005.

HUNGRIA, M.; CAMPO, R.J.; MENDES, I.C. A importância do processo de fixação biológica do nitrogênio para a cultura da soja: componente essencial para a competitividade do produto brasileiro. Londrina: Embrapa Soja, p. 80, 2007.

INCAPER, sistemas de informações meteorológicas. Disponível em: <http://hidrometeorologia.incaper.es.gov.br> Acesso em 05 de Junho de 2015.

MALAVOLTA, E.; VITTI, G.C.; OLIVEIRA, S.A. Avaliação do estado nutricional das plantas: princípios e aplicações. 2 ed. Piracicaba: Potafos, p. 319, 1997. 
MENNA, P.; HUNGRIA, M. Phylogeny of nodulation and nitrogen-fixation genes in Bradyrhizobium: Supporting evidences for the theory of monophyletic origin and spread and maintenance by both horizontal and vertical transfer. International Journal of Systematic and Evolutionary Microbiology. doi: 10.1099/ijs.0.028803$0,2011$.

PADOVAN, M. P.; MOTTA, I. de Sá; CARNEIRO, L. F.; MOITINHO, M. R. ; FERNANDES, S. S.L. Acúmulo de fitomassa e nutrientes e estádio mais adequado de manejo do feijãode-porco para fins de adubação verde. Revista Brasileira de Agroecologia. 6(3): 182-190 (2011).

SILVA, G.; LIMA, A.; NOSOLINE, S.; RUMJANEK, N.; XAVIER, G. Seleção de inoculante rizobiano para feijão-de-porco. Revista Brasileira de Agroecologia/ Vol.2 No. 2, out. 2007.

SORATTO R. P.; CARVALHO, M. A. C. de; ORIVALDO ARF, O. Teor de clorofila e produtividade do feijoeiro em razão da adubação nitrogenada. Pesquisa agropecuária brasileira, Brasília, v.39, n.9, p.895-901, set. 2004. 